\title{
Evaluation of Health Symptoms and Exposures Among Employees at a Flooring Manufacturing Plant
}

\section{Sophia Chiu, MD, MPH}

Jessica F. Li, MSPH

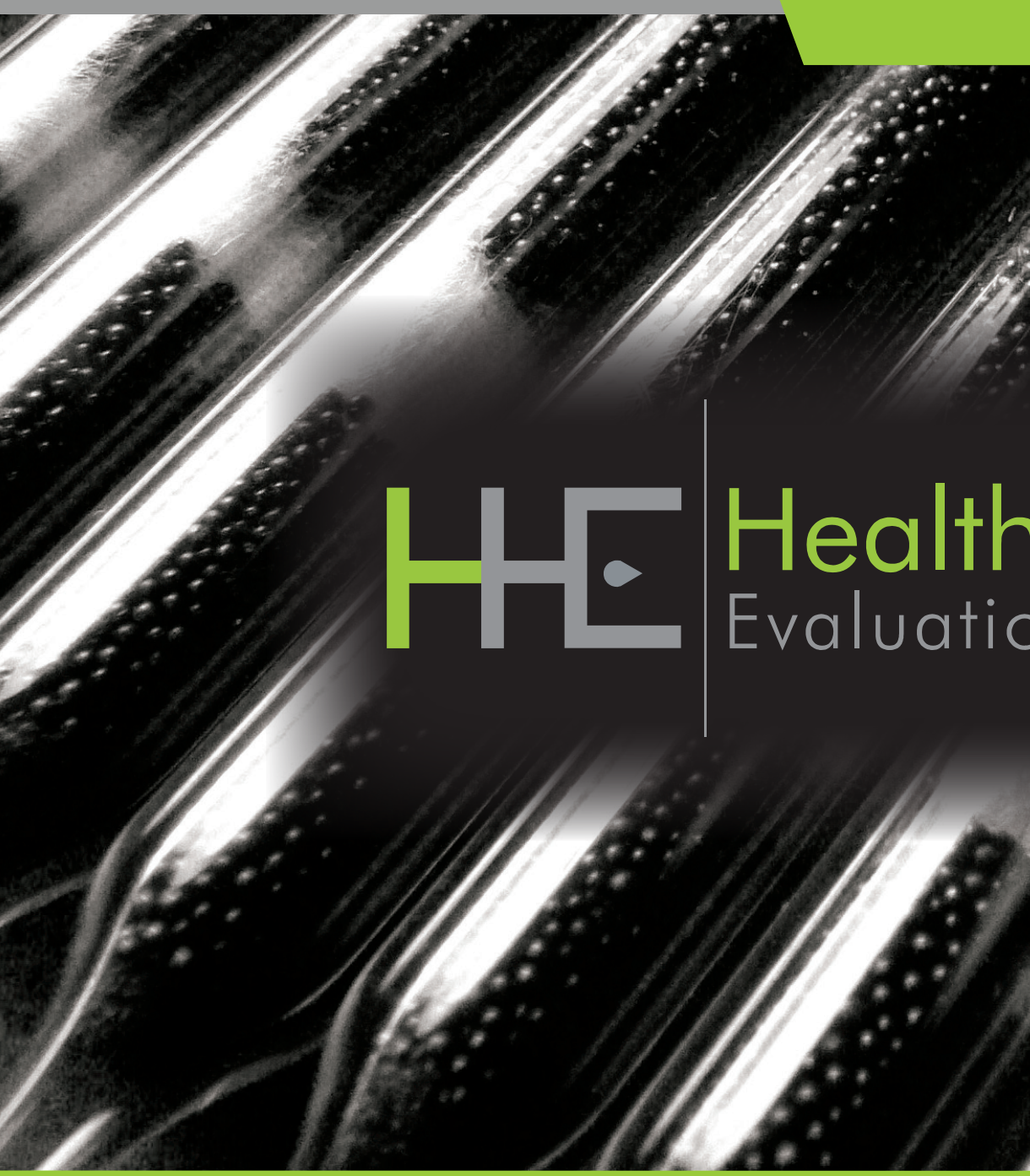

HHE Report No. 2016-0126-3301 January 2018

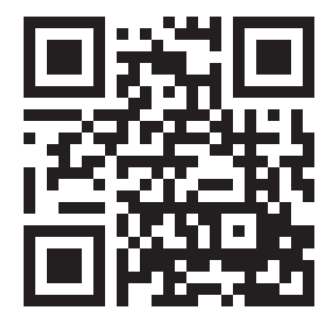

Centers for Disease Control

and Prevention

National Institute for Occupational

Safety and Health 


\section{Contents}

Highlights.

Abbreviations ................................... iii

Introduction ................................... 1

Methods ............................................. 2

Results ............................................... 5

Discussion ........................................ 9

Conclusions ..................................... 11

Recommendations.......................... 12

Appendix $\ldots \ldots \ldots \ldots \ldots \ldots \ldots \ldots \ldots \ldots \ldots \ldots \ldots \ldots \ldots$

References ....................................... 16

Acknowledgements.......................... 19

The employer is required to post a copy of this report for 30 days at or near the workplace(s) of affected employees. The employer must take steps to ensure that the posted report is not altered, defaced, or covered by other material.

The cover photo is a close-up image of sorbent tubes, which are used by the HHE Program to measure airborne exposures. This photo is an artistic representation that may not be related to this Health Hazard Evaluation. Photo by NIOSH. 


\section{Highlights of this Evaluation}

The Health Hazard Evaluation Program received a request from employees at a flooring manufacturing plant. Employees were concerned about respiratory exposures when polyvinyl chloride resin overheated ("burnt mix") and skin exposures during the ultraviolet-cured vinyl tile coating operation.

\section{What We Did}

- We reviewed prior sampling results, written policies and procedures, and injury and illness logs.

- We interviewed employees about their work and health. We classified their symptoms into "workrelated" and "non-work-related."

- We sampled the air for hydrogen chloride, carbon monoxide, nitrogen dioxide, and nitric oxide (nitrous fumes) along the luxury vinyl tile production line.

- We tested the air for volatile organic compounds.

- We evaluated the local exhaust ventilation near the luxury vinyl tile line.

\section{What We Found}

- No instances of the polyvinyl chloride resin overheating occurred during our evaluation, so we were unable to evaluate a burnt mix event.

- Half of 46 interviewed employees reported at least one work-related symptom over the past 3 months. The most common work-related symptoms were sore throat, cough, and eye irritation.

- Most employees with work-related symptoms reported eye, nose, or throat irritation. Fourteen employees reported work-related lower respiratory

We evaluated symptoms and work practices during luxury vinyl tile manufacturing. Employees in hot mix areas were twice as likely to report workrelated irritation symptoms as other production employees, but air levels of various chemicals were low or undetectable during normal production conditions. No "burnt mix" events occurred during our evaluation. Most employees who handled ultraviolet-cured coating, a skin sensitizer, reported skin contact. We recommended improved tracking and communication of "burnt mix" events and more consistent use of skin protection and hand cleaner when handling ultraviolet-cured coating. symptoms such as shortness of breath, wheeze, and chest tightness.

- Luxury vinyl tile production employees in the mix, extruder, and calendar areas were twice as likely to report work-related irritation symptoms as other production employees.

- Most employees handling the ultraviolet-cured coating, a skin sensitizer, reported getting it on their exposed forearm or upper arm skin. Few wore long-sleeved uniforms or protective sleeves. 
- Temperature controls and installing additional exhaust hoods had reportedly reduced the employees' symptom frequency.

- We measured low or undetectable levels of chemicals, but we were not able to characterize all exposures that might occur during burnt mix events.

\section{What the Employer Can Do}

- Monitor mix temperatures during production and track when burnt mix occurs.

- Inform employees when burnt mix is occurring.

- Educate employees about the potential risks of exposure to burnt mix and how to protect themselves from it.

- Encourage employees to report work-related symptoms or other health concerns. Investigate possible causes and correct problems.

- Educate employees who use N95 filtering facepiece respirators on a voluntary basis during non-burnt mix conditions that they do not protect against gases such as hydrogen chloride, a gas that is generated during burnt mix events.

\section{What Employees Can Do}

- Report work-related health concerns to your supervisor. Irritation and respiratory symptoms can be signs that the production process is not functioning optimally.

- Seek medical care if you have symptoms to determine if they are related to exposures at work. If so, proper accommodations or improvements to your work environment should be requested.

- Understand that N95 filtering facepiece respirators do not protect against gases like hydrogen chloride. Protection would require a different type of respirator.

- Use appropriate gloves and sleeves to cover the hands, wrists, and forearms when handling ultraviolet-cured coating. Afterwards, use appropriate hand cleaner instead of soap and water. 


\section{Abbreviations}

ACGIH ${ }^{\circledR} \quad$ American Conference of Governmental Industrial Hygienists

CFR

EPA

$\mathrm{HCl}$

LVT Code of Federal Regulations

NIOSH

OEL

OSHA

PEL

PVC

ppm

REL

TLV®

TWA

Environmental Protection Agency

UV

Hydrogen chloride

Luxury vinyl tile

National Institute for Occupational Safety and Health

Occupational exposure limit

Occupational Safety and Health Administration

Permissible exposure limit

Polyvinyl chloride

Parts per million

Recommended exposure limit

Threshold limit value

Time-weighted average

Ultraviolet

VOC Volatile organic compound 
This page left intentionally blank 


\section{Introduction}

The Health Hazard Evaluation Program received a request for an evaluation from employees at a flooring manufacturing plant. Employees were concerned about coughing, difficulty breathing, sinus problems, nasal symptoms, and sore throat associated with overheating of polyvinyl chloride (PVC) resin used to make luxury vinyl tile (LVT). Employees were also concerned about skin reactions thought to be associated with the LVT ultraviolet (UV)-cured coating operation. We visited the plant in January 2017. After the visit, we sent interim letters to the company and employee representatives summarizing our activities and preliminary findings in January 2017.

\section{Process Description}

LVT manufacturing began at this plant in the spring of 2015. At the time of the site visit, LVT production was operating 24 hours per day, 7 days per week, with three 8 -hour shifts. LVT manufacturing occurred in its own building on one continuous production line. Approximately 80 production employees worked in this building.

To produce LVT, raw materials such as limestone, PVC resin, coloring agents, and liquid terephthalate-based plasticizers were mixed and heated. These raw materials were mixed in a blender before being extruded and calendared (use of rollers to smooth and compress) to form a flattened blanket of hot base material either 3 feet or 4 feet wide. Operators monitored the mixing, extruding, and calendaring operations. At the film roll station, a laminate consisting of the desired printed pattern and clear top film was attached to one side of the base material in the drum operation. The uncut laminated LVT blanket was cooled in a water bath before being cut with a punch press into smaller pieces depending on the style of tile being produced.

Cut tile pieces traveled via conveyer belt to the quality control area where operators visually inspected tiles and diverted imperfect pieces to a granulator for recycling. Acceptable tile pieces were then conveyed to an enclosed operation where a urethane-based UV-cured coating was automatically applied. Some tiles received further cutting to create edge profiles before being packaged into cardboard boxes.

\section{Burnt Mix}

"Burnt mix" was the term company managers and employees used to describe the situation where an unexpected line stoppage resulted in the blended LVT mix overheating and exceeding temperatures of $405^{\circ} \mathrm{F}-420^{\circ} \mathrm{F}$. When heated above this temperature range, the LVT mix could thermally decompose and release hydrogen chloride $(\mathrm{HCl})$, a gas that forms hydrochloric acid in the air, which could be very irritating to the eyes and upper airways. If the burnt mix occurred during mixing, employees could divert the mix to collection bins that were covered by an exhaust hood and a fire-resistant blanket. Company policy instructed employees to leave the burnt mix under an exhaust hood and blanket for 8 hours before moving the covered bins of burnt mix outside the building to further cool before disposing into a dumpster. If the burnt mix occurred during extrusion, company policy instructed employees to cover bins containing burnt mix with a fire-resistant blanket before moving the bin outside the building for further cooling before disposal into a dumpster. 
According to company managers, certain engineering controls had been implemented since the LVT line began to reduce the frequency of burnt mix events. Process adjustments were still being made when the employees requested the health hazard evaluation. For example, temperature controls were installed to reduce the likelihood of burnt mix from occurring and to prevent burnt mix from reaching the extruder where it was more difficult to remove. In addition, local exhaust hoods had been installed over the burnt mix collection bins, additional exhaust hoods had been installed over the line at the film roll station and at the calendars, and two large ceiling fans had been installed to dilute LVT line emissions.

\section{Personal Protective Equipment and Work Practices}

At the time of our visit, anyone entering the LVT production area was required to wear a bump cap or hard hat, eye protection, hearing protection, and steel-toe shoes. The employer supplied safety glasses that blocked the UV wavelengths that were used to cure the liquid coating. When refilling the urethane-based UV coating liquid reservoirs on the conveyor line, employees were required to wear 8-mil thick wrist-length nitrile gloves, protective arm sleeves, aprons or coveralls, shoe coverings, and face shields if the employee determined there was a potential for splashing. A commercially available UV hand cleaner was supplied to remove UV coating from the skin.

At the time of our evaluation in January 2017, the plant was implementing a revised respiratory protection program to address citations from the Occupational Safety and Health Administration (OSHA). The revised plan required employees (mostly LVT line operators) to wear full-face respirators with acid gas cartridges when covering bins containing burnt mix and moving burnt mix bins from the LVT line to the outside. Employees in the respiratory protection program were medically cleared, trained, and fit-tested for respirator use in December 2016. N95 filtering facepiece respirators were also provided to employees for voluntary use under normal operating conditions. The company's job safety analysis documents erroneously used the term "dust mask" as a synonym for N95 filtering facepiece respirators.

\section{Methods}

The objectives of our evaluation were to:

1. Assess the prevalence of work-related symptoms among LVT line employees.

2. Determine the prevalence of work-related respiratory symptoms and the extent that they resulted from normal LVT operations or burnt mix conditions.

3. Evaluate skin reactions and dermal exposures to LVT employees associated with the UV-cured coating operation.

\section{Document Review}

We reviewed past industrial hygiene sampling records, OSHA's Form 300 Log of WorkRelated Injuries and Illnesses from 2015 and 2016, and records related to an incident in June 2016. We also reviewed two reports for OSHA inspections of the LVT line conducted in August 2015 and July 2016. 


\section{Employee Interviews}

The employer provided a roster of 126 LVT employees that included job title, job description, shift, and whether the employee was in the respiratory protection program because he or she might be involved in handling potential burnt mix. In addition to the approximately 80 production employees (operators), job categories included electrician, mechanic, salaried, and support personnel.

We decided to invite first and second shift employees in all job categories to participate in confidential medical interviews. Of the 93 employees scheduled to work on the first and second shifts during our site visit, we selected 52 (56\%) to invite for confidential medical interviews. Figure 1 outlines how we chose employees to invite for interviews. We chose all six employees in the respiratory protection program and both employees with the job title of UV coater operator for interviews. For the remaining 44 interview slots, we used a convenience sample. We chose at least one employee for each remaining unique job title in the operator job description category (31 employees) and employees within the mechanic, salaried, and support job description categories (13 employees) at random.

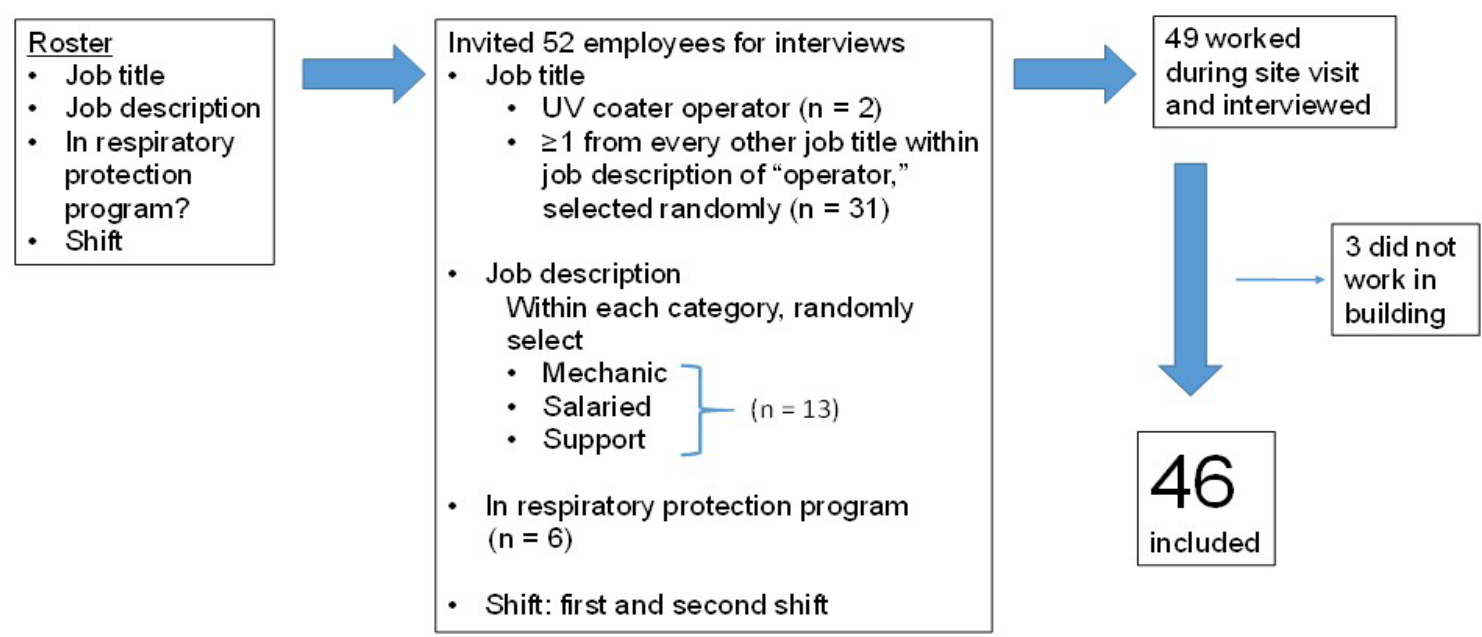

Figure 1. Diagram of how LVT employees were invited for interviews and included in the data analysis. 
During the interviews, we discussed work history and practices, symptoms, medical history, and demographic information. We also examined the skin on participants' hands and forearms. We asked about symptoms that occurred in the past 3 months. We asked participants to not include symptoms that they thought were associated with a cold or respiratory infection. We classified a symptom as work-related if the participant reported experiencing the symptom while working on the LVT line and the symptom got better on weekends or vacations away from work. We grouped eye irritation, nose irritation, and sore throat as irritation symptoms and cough, shortness of breath, wheeze, and chest tightness as respiratory symptoms.

We summarized descriptive statistics for demographic, work, and health information. We classified production employees who reported currently working in the mix, extruder, and calendar areas as hot mix production employees. We calculated prevalence ratios and 95\% confidence intervals by comparing the prevalence of work-related irritation and respiratory symptoms among hot mix production employees and production employees who did not work in hot mix areas. We compared the characteristics of hot mix production employees to production employees who did not work in hot mix areas using the Mann-Whitney U test for continuous variables and Fisher's exact test for categorical variables. All statistical tests were two-sided; statistical significance was set at $P<0.05$. We used $\mathrm{R}$ version 3.3.2 to perform statistical analyses.

\section{Exposure Assessment}

We measured nitric oxide (nitrous fumes), nitrogen dioxide, $\mathrm{HCl}$, and carbon monoxide concentrations present in the air throughout the LVT line using Dräger colorimetric gas detector tubes and a Dräger Accuro ${ }^{\circledR}$ pump. These instantaneous measurements for gases were taken at extruder \#1, at the air hose after calendar \#2 during normal conditions, and at calendar \#2 when the mix was overheated and degraded but not considered burnt mix. Three sets of measurements were taken from approximately 10:00 a.m. to 11:30 a.m. The measurement ranges for the colorimetric tubes are 2-100 parts per million (ppm) for nitrous fumes, $0.1-30 \mathrm{ppm}$ for nitrogen dioxide, $0.2-20 \mathrm{ppm}$ for $\mathrm{HCl}$, and 2-300 ppm for carbon monoxide. Full-shift personal samples were not collected due to the rare occurrence of burnt mix events. Past personal sampling by a consultant and by OSHA indicated low levels of these gases during normal operating conditions.

We used thermal desorption tubes to collect area air samples for volatile organic compounds (VOCs) according to Environmental Protection Agency (EPA) Method TO-17 [EPA 1999]. These screening samples were collected by laminate application at the drum, extruder \#1, extruder \#2, and UV coater operator station. The thermal desorption tube results were used to qualitatively identify VOCs produced during LVT production and to determine which VOCs we could quantitatively analyze for in side-by-side area air samples collected using charcoal tubes. Samples were collected in the morning and afternoon.

We observed work processes, work practices, and workplace conditions. We used ventilation smoke tubes to observe airflow patterns near the film roll station and near both mixers. 


\section{Results}

\section{Past Sampling}

In November 2015, an industrial hygiene consultant collected 15-minute personal air samples for $\mathrm{HCl}$. Air samples were taken on a LVT line operator removing burnt mix from the building immediately following a burnt mix event and on a calendar operator working on the LVT line during normal conditions. Neither employee was wearing respiratory protection. In both situations, the 15-minute time-weighted average (TWA) exposures were below the OSHA ceiling limit of $5 \mathrm{ppm}$ and American Conference of Governmental Industrial Hygienists ${ }^{\circledR}(\mathrm{ACGIH})$ ceiling limit of $2 \mathrm{ppm}$.

In 2016, an industrial hygiene consultant for the company conducted environmental sampling. These results are summarized below (Table 1).

Table 1. Summary of environmental sampling results performed in 2016

\begin{tabular}{|c|c|c|c|c|c|c|}
\hline Dates & $\begin{array}{c}\text { Respirable } \\
\text { dust } \\
\left(\mathrm{mg} / \mathrm{m}^{3}\right)\end{array}$ & $\begin{array}{c}\mathrm{HCl} \\
\text { (ppm) }\end{array}$ & $\begin{array}{c}\text { Nitrogen } \\
\text { dioxide } \\
\text { (ppm) }\end{array}$ & $\begin{array}{l}\text { Nitric } \\
\text { oxide } \\
\text { (ppm) }\end{array}$ & $\begin{array}{l}\text { Carbon } \\
\text { monoxide } \\
(\mathrm{ppm})^{*}\end{array}$ & Comments \\
\hline $1 / 13-14$ & $0.042-1.5$ & $0.2-0.7 \dagger$ & $\begin{array}{c}0-0.17 \ddagger \\
0.1-0.5 \dagger \\
0-0.03\end{array}$ & $0-0.64$ & $\begin{array}{c}0-2.4 \\
0-3.5 \dagger\end{array}$ & $\begin{array}{c}\text { LVT line operated at } \\
\text { about } 12 \% \text { capacity for } \\
\text { first } 24 \text { hours, then about } \\
100 \% \text { capacity for } \\
4 \text { hours during sampling. }\end{array}$ \\
\hline $3 / 2-3$ & $0.042-1.4$ & $0.3-1.2 \dagger$ & $\begin{array}{c}0-0.20 \ddagger \\
0-0.3 \dagger \\
0-0.051\end{array}$ & $13-24$ & $\begin{array}{c}0-2.9 \\
0-4.5 \dagger\end{array}$ & $\begin{array}{l}\text { LVT line operated at } \\
\text { about } 80 \% \text { capacity } \\
\text { during } 24 \text { hours of } \\
\text { sampling. }\end{array}$ \\
\hline $7 / 26-27$ & $0.043-1.9$ & $0.2-1.5 \dagger$ & 0 & $0-3.7$ & $\begin{array}{c}0-0.026 \\
0-3.5 \dagger\end{array}$ & $\begin{array}{l}\text { LVT line operated at } \\
\text { about } 75 \% \text { capacity over } \\
24 \text { hours of sampling. } \\
\text { Overhead and personnel } \\
\text { doors were open, an } \\
\text { atypical work practice. }\end{array}$ \\
\hline $\begin{array}{l}\mathrm{NIOSH} \\
\text { REL }\end{array}$ & None & $5 \dagger$ & $1 \neq$ & 25 & $\begin{array}{c}35 \\
200 \dagger\end{array}$ & - \\
\hline $\begin{array}{l}\text { OSHA } \\
\text { PEL }\end{array}$ & 5 & $5 \dagger$ & $5 \dagger$ & 25 & 50 & - \\
\hline $\begin{array}{l}\text { ACGIH } \\
\text { TLV }\end{array}$ & None & 2 & 0.2 & 25 & 25 & - \\
\hline
\end{tabular}

$\mathrm{mg} / \mathrm{m}^{3}=$ milligrams per cubic meter

$\mathrm{NIOSH}=$ National Institute for Occupational Safety and Health

$\mathrm{OEL}=$ Occupational exposure limit

$\mathrm{PEL}=$ Permissible exposure limit

REL $=$ Recommended exposure limit

TLV $=$ Threshold limit value

${ }^{*}$ Averages reported from a direct-reading instrument

†Ceiling limit that should never be exceeded

$\ddagger 15$-minute short-term OEL 
The results shown in Table 1 cannot be directly compared to OELs. However, if it is assumed that these area air sample results are indicative of employee exposures in the sampled areas, all of the airborne exposures were well below the lowest applicable OELs for respirable dust, $\mathrm{HCl}$, nitrogen dioxide, and carbon monoxide. However, nitric oxide levels of $24 \mathrm{ppm}$ at the mixing station in March 2016 were close to the 8-hour TWA OEL of $25 \mathrm{ppm}$. Nitric oxide levels were lower during the following round of sampling in July 2016 when overhead and personnel doors were open.

\section{OSHA Logs}

In 2015 and 2016, seven of eight recorded incidents in the OSHA 300 Logs for the plant involved the LVT line. Of the seven incidents related to the LVT line, six consisted of musculoskeletal injuries. The other incident involved illness related to acute inhalational exposure of mix from extruder \#1 in June 2016.

According to company records, in the June 2016 incident an employee breathed in dry, dusty mix upon opening the door of extruder \#1 to investigate a possible malfunction. No area or personal air samples were taken during this incident. No respiratory protection was required for this task in the company's job safety analysis. The employee developed difficulty breathing and coughing and was taken to the local emergency department for further evaluation.

\section{OSHA Inspections}

In response to an employee complaint, OSHA conducted an inspection in August 2015 and collected air samples for $\mathrm{HCl}$, but not during a burnt mix event. $\mathrm{No} \mathrm{HCl}$ was detected (minimum detectable concentration not provided), but OSHA issued a citation for lack of training on chemical hazards, not providing employees with Appendix D of the OSHA respiratory protection standard for voluntary respirator use, and not providing employees with the appropriate respirator for handling burnt mix.

In response to the June 2016 incident, OSHA conducted another inspection and collected air samples for $\mathrm{HCl}$ and phosgene in July 2016, but again not during a burnt mix event. $\mathrm{No} \mathrm{HCl}$ or phosgene was detected. In December 2016, OSHA issued a citation for the lack of changeout schedule for respirators and for not providing employees with training and fit testing required to use a respirator.

\section{Employee Interviews}

\section{Demographic, Work, and Health Characteristics of Interviewed Employees}

Of the 52 LVT employees we selected to invite for interviews on the basis of who was scheduled to work, three were not working during our site visit. All 49 employees (100\%) who were working on the days of our site visit participated. Although their job duties involved the LVT line, one salaried employee and two support employees reported that, on average, they did not regularly work in the building where the LVT line was housed. Because they reported only occasionally walking through or bringing supplies into the LVT building, we excluded them from further analysis; this left 46 employees in the analysis (Figure 1). Of the 46 employees, 39 (85\%) were male. The median age was 46 years (range: $23-64$ 
years). Employees worked for a median of 46 hours per week (range: 5-65 hours per week) and 18 months (range: 2-30 months) on the LVT line.

According to the roster, 35 (76\%) of the 46 employees were production employees. Of these, $18(51 \%)$ employees reported currently working in the mix, extruder, or calendar area. We classified them as hot mix production employees. This included all six employees in the respiratory protection program because they were identified by the employer as potentially having to handle burnt mix. In addition, 11 nonproduction employees reported currently working in these areas, for a total of 29/46 (63\%) employees working in the hot mix areas.

Perceptions of how often burnt mix events occurred during the work shift varied widely among interviewed employees. Responses ranged from once per year to once per shift. Some employees commented that they thought burnt mix was occurring based on the smell. Seventeen (37\%) interviewed employees said they did not know how often burnt mix happened during their work shift.

Eighteen (39\%) interviewed employees reported handling burnt mix. This included 12 employees who reported currently working in hot mix areas. The other six employees were production employees who worked in the drum, water bath, granulator, press, UV coating, inspection, and packaging areas. When handling burnt mix, 12 (67\%) employees reported using a N95 respirator, dust mask, or an unspecified type of respirator.

Eleven (24\%) interviewed employees reported ever handling UV coating. Ten employees reported always washing their hands after handling UV coating, and one employee reported sometimes washing his hands. Six employees reported washing their hands with the UV hand cleaner, and four employees reported using soap and water. All 11 employees reported wearing gloves when handling UV coating, but only three reported wearing a long-sleeved uniform or protective sleeves. Nine of 11 employees reported that their skin has come into contact with UV coating. The most common body part coming into contact with UV coating was the forearm or upper arm, followed by hand and wrist. All nine employees reported being able to wash off the area right away.

All interviewed employees reported always using a bump cap or hard hat, safety glasses, hearing protection, and steel toe shoes as required for entry in the LVT production area, except for one employee who reported sometimes using hearing protection. In addition, 45 interviewed employees (98\%) reported wearing gloves as part of their job duties.

Two of 46 (4\%) interviewed employees reported currently having asthma that was diagnosed by a healthcare provider before working on the LVT line. One employee reported that the asthma seemed worse at work. Fifteen of 46 interviewed employees (33\%) were current smokers.

\section{Work-related Symptoms}

Half of the interviewed employees reported at least one work-related symptom during the past 3 months. The most commonly reported work-related symptoms were sore throat (37\%), cough (26\%), and eye irritation (24\%). Figure 2 summarizes the work-related symptoms reported by the 46 interviewed employees. 


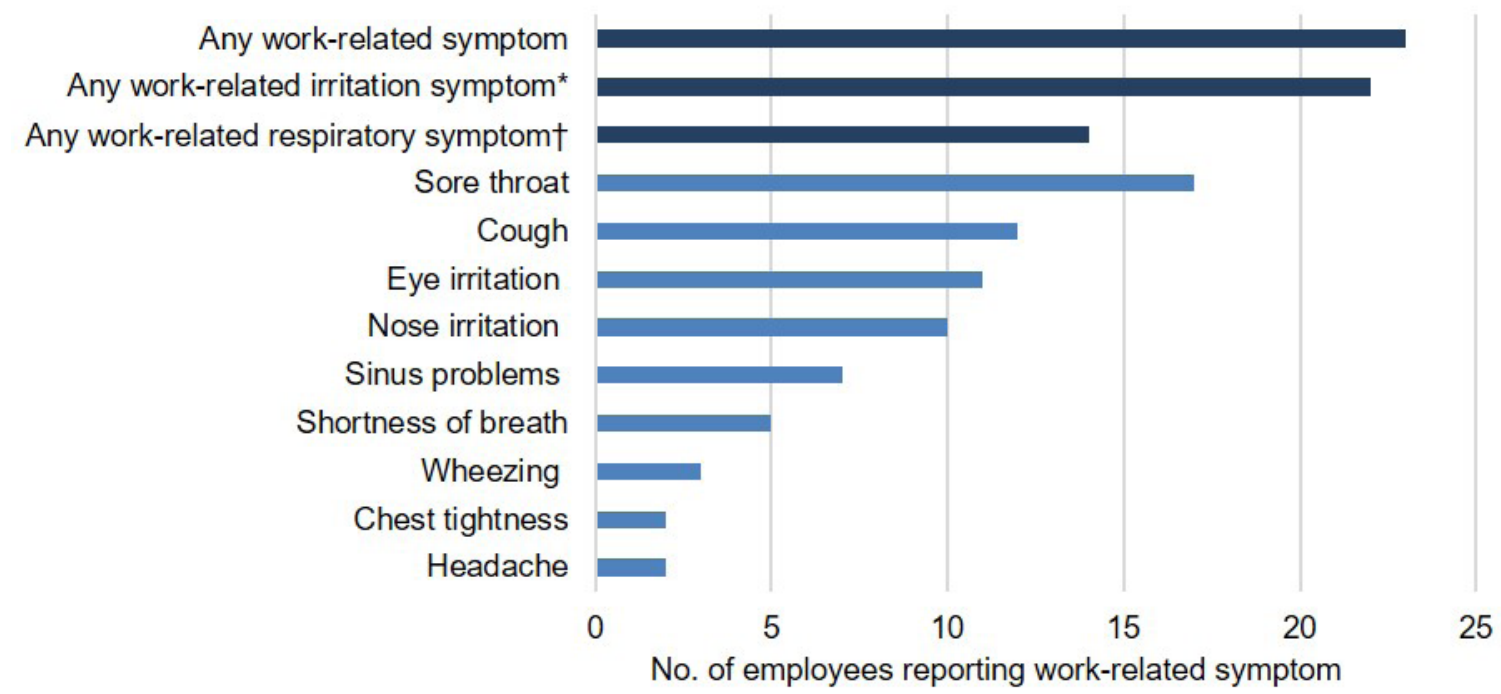

*Work-related eye irritation, nose irritation, and sore throat †Work-related shortness of breath, wheeze, and chest tightness

Figure 2. Number of employees reporting work-related symptoms during the past 3 months $(n=46)$.

Among the 18 hot mix production employees, the most common work-related symptoms were sore throat (56\%), eye irritation (39\%), and cough $(33 \%)$. Hot mix production employees were twice as likely to report work-related irritation symptoms compared to other production employees (prevalence ratio $=2.05,95 \%$ confidence interval $=(1.01-4.14)$ ), but not more likely to report work-related respiratory symptoms (prevalence ratio $=1.32,95 \%$ confidence interval $=(0.52,3.37))$. Similar proportions of hot mix production employees and other production employees were male $(78 \%$ vs. $88 \%, P=0.66)$ and current smokers (33\% vs. $41 \%, P=0.73$ ). The median age of hot mix production employees (48 years, range: 23-63 years) and other production employees (43 years, range: 29-60 years) was similar $(P=0.56)$. There was no statistically significant difference in median job tenure on the LVT line between hot mix production employees (18 months, range: 3-24 months) and other production employees (12 months; range: 3-24 months) $(P=0.44)$.

Three interviewed employees (7\%), consisting of one UV coater operator and two LVT production employees working in other areas, reported experiencing skin irritation during the past 3 months. The UV coater operator reported UV coating coming into contact with the forearm, which was the site of the skin irritation and a rash. At the time of interviews, the skin on the employees' hands and forearms appeared unremarkable, except for four employees (9\%) with cuts and scratches that they reported had happened at work. No rashes were identified.

\section{Air Sampling}

The thermal desorption tube analyses identified the following VOCs: benzene, ethylbenzene, styrene, toluene, and xylene. On the basis of these results, we analyzed for these substances 
on charcoal sorbent tubes collected at the drum, extruder \#1, extruder \#2, and UV coater operator station. None of these VOCs were detected (less than 23 parts per billion).

Nitric oxide (nitrous fumes), nitrogen dioxide, and $\mathrm{HCl}$ were not detected using Dräger colorimetric detector tubes at extruder \#1 or calendar \#2 during normal or overheated mix conditions. We measured carbon monoxide concentrations of about $2 \mathrm{ppm}$ at the air hose by calendar \#2 during normal conditions, but not during overheated conditions. The colorimetric tubes have a detection limit of $2 \mathrm{ppm}$ for nitrous fumes, $0.1 \mathrm{ppm}$ for nitrogen dioxide, $0.2 \mathrm{ppm}$ for $\mathrm{HCl}$, and $2 \mathrm{ppm}$ for carbon monoxide.

\section{Ventilation}

Using ventilation smoke tubes, we determined that the local exhaust system at mixer \#2 was not effectively capturing process emissions. One reason for this was the excess flexible duct and sharp bends in the duct at mixer \#2 (Figure 3), conditions that can diminish the efficiency of an exhaust ventilation system. Additionally, we saw canopy hoods on the LVT manufacturing line that exhausted airborne contaminants through the breathing zone of the operators, and pedestal fans at operators' work stations that could interfere with local exhaust ventilation effectiveness.

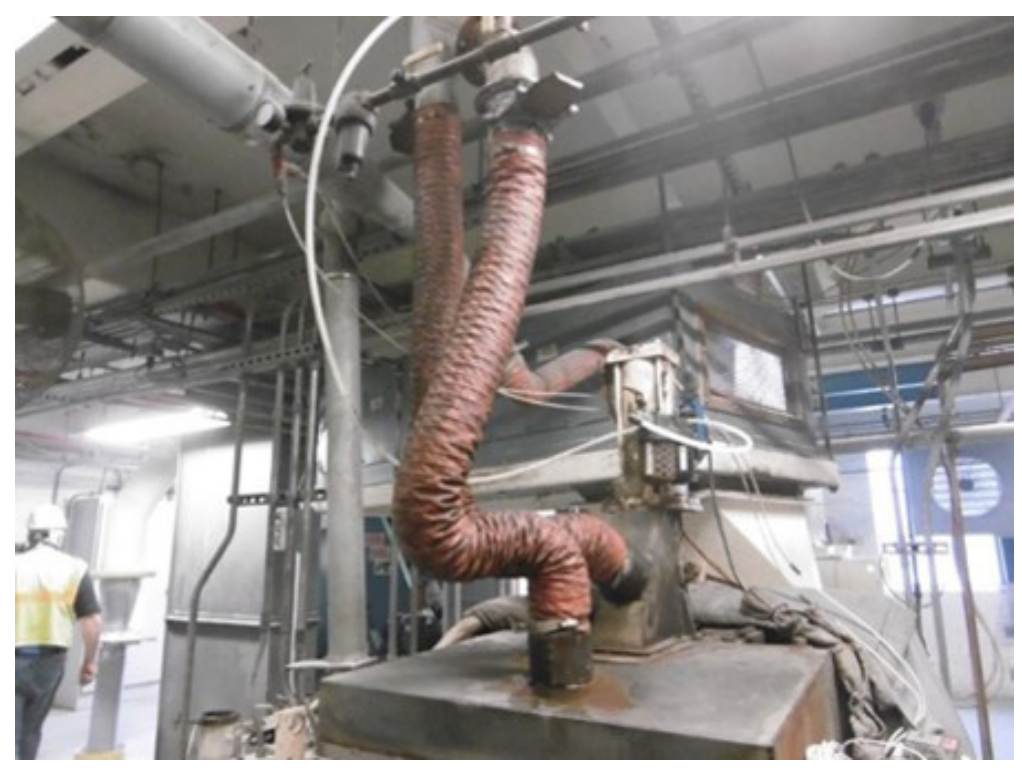

Figure 3. Excess flexible duct and bends in duct above mixer \#2. Photo by NIOSH.

\section{Discussion}

Prior to our site visit in January 2017, process improvements occurred as the plant gained experience with the new LVT line. No burnt mix incidents were documented the 3-month period before our visit. However, employees reported work-related symptoms during those 3 months that are consistent with symptoms described in prior studies of workers exposed to PVC thermal degradation products. At the time of those studies, PVC likely included other 
substances associated with symptoms, such as phthalates [Jaakkola and Knight 2008; Nielsen et al. 1989]. The most common symptoms reported by LVT employees were sore throat, cough, and eye irritation. Production workers who work near hot mix were approximately twice as likely to report work-related irritation of the eye, nose, and throat as production employees in other LVT production areas. Hot mix production employees and other production employees were similar in age, job tenure on the LVT line, age and sex distribution, and current smoking status. However, hot mix production employees were not more likely to report respiratory symptoms such as shortness of breath, wheeze, and chest tightness, which would be more concerning for long-term health effects than short-term irritation symptoms.

We could not identify a specific cause of these symptoms on the basis of our sampling and review of prior sampling results. During our site visit, we found levels of carbon monoxide of approximately 2 ppm near calendar \#2 and nondetectable levels of nitric oxide, nitrogen dioxide, and $\mathrm{HCl}$. The relatively high proportion of LVT employees who reported workrelated symptoms when no burnt mix events were documented suggest that symptoms might not be occurring only during or immediately after burnt mix conditions. Therefore, it is important for employees to report any work-related symptoms to their supervisors so that efforts can be made to identify possible causes and correct problems.

We found that perceptions of how often burnt mix events occurred varied widely among interviewed employees. Approximately one third did not know how often burnt mix events occurred during their work shift. Some employees commented that their perception of burnt mix events happening was based on smell. However, smell might not be a reliable indicator of when mix reaches the temperature range when thermal decomposition occurs and $\mathrm{HCl}$ is released. Therefore, monitoring the temperature of the mix during the production process and clear, timely communication of burnt mix incidents to employees can help them accurately understand what is happening in the workplace. Moreover, this communication would allow designated employees to prepare for handling burnt mix, for example, by assembling and putting on required personal protective equipment.

Our site visit occurred shortly after the company revised the respiratory protection program to address an OSHA citation. Employees who might handle burnt mix were in a respiratory protection program by the time of our site visit. However, the number of interviewed employees who reported handling burnt mix with or without respiratory protection was higher than the number of interviewed employees in the respiratory protection program. Employees reported using N95 respirators or dust masks, which do not protect against gases such as $\mathrm{HCl}$, instead of the designated full-face respirator with an acid gas cartridge. These findings suggest that employees' responses might refer to their experience before the respiratory protection program was revised or that additional employees need to be enrolled in the revised respiratory protection program. Managers should ensure that all employees who handle burnt mix have received appropriate training and are using appropriate respiratory protection. Employees who use N95 filtering facepiece respirators on a voluntary basis should receive training that N95 respirators do not protect against gases that might be generated during burnt mix events and are not appropriate for use during these events. 
We found that approximately $33 \%$ of interviewed employees were current smokers, which is higher than the $20 \%$ of current smokers among working adults in the United States [Centers for Disease Control and Prevention 2011]. The higher prevalence of work-related irritation symptoms among hot mix production employees compared to other production employees cannot be attributed to current smoking status because the proportion of current smokers in both groups were similar. In general, smoking cessation can decrease respiratory symptoms such as cough and wheeze [Willemse et al. 2004]; work-related cough was the second most common work-related symptom interviewed employees reported.

We found that few employees had skin irritation in the past 3 months. However, most employees who handle UV coating reported that it came into contact with their skin. This included one employee who developed a rash and skin irritation in the area of contact. UV-curable urethane-based inks, like the ones used at this plant, are skin sensitizers. Skin sensitizers are chemicals that can result in allergic reactions with repeated exposure, even if they do not cause skin reactions immediately [NIOSH 2013]. In one study, seven workers exposed to UV-curable urethane-based inks developed contact dermatitis [Nethercott et al. 1983]. Thus, preventing skin contact and promptly removing UV coating from the skin are important to preventing skin sensitization. However, most employees reported using soap and water instead of the UV hand cleaner to remove UV coating from their skin.

This evaluation had several limitations. First, no data were available about when burnt mix occurred in relation to work-related symptoms reported by employees. The company was unable to provide records of when burnt mix occurred during the 3 months prior to our site visit, the time period we asked about symptoms in the interviews. We did not observe any burnt mix events during our visit. Only one sampling event by the plant's industrial hygiene consultant included personal air samples collected while an employee removed burnt mix from the building immediately following an event. Because burnt mix events are sporadic, a prudent occupational safety and health approach would not be solely based on exposure levels during burnt mix events. Instead, a preferable strategy would be to monitor the temperature of hot mix, implement controls to reduce the likelihood of burnt mix occurring, and have contingency plans to handle burnt mix safely if it does occur. Second, we found wide variation in employee perceptions about burnt mix, which might have affected responses to some interview questions. Finally, we did not interview all LVT employees over all three shifts. We attempted to interview all employees in the respiratory protection program and employees in a variety of job titles and description over two shifts. However, all employees selected for interviews who were working on the days of our site visit participated. We still found that hot mix production employees were more likely to have work-related irritation symptoms than production employees in other areas.

\section{Conclusions}

Employees who worked near hot mix were approximately twice as likely to report workrelated irritation symptoms as employees in other LVT production areas. We were unable to attribute this finding to specific exposures because we measured low (carbon monoxide) or nondetectable (nitrous fumes, nitrogen dioxide, $\mathrm{HCl}$, VOCs) levels in the work area. However, because we observed no burnt mix during our evaluation, we were not able to 
characterize all exposures that may occur during those events. Because burnt mix events are sporadic and unplanned, monitoring mix temperatures during production should help prevent it from occurring. Communicating with employees about avoiding burnt mix and ensuring that appropriate training and personal protective equipment are provided for employees who handle burnt mix should further reduce work-related irritation symptoms. Most employees who handled UV coating reported skin contact with the UV coating, a known skin sensitizer, but few reported skin symptoms.

\section{Recommendations}

On the basis of our findings, we recommend the actions listed below. We encourage the plant to use a labor-management health and safety committee or working group to discuss our recommendations and develop an action plan. Those involved in the work can best set priorities and assess the feasibility of our recommendations for the specific situation at the plant.

Our recommendations are based on an approach known as the hierarchy of controls. This approach groups actions by their likely effectiveness in reducing or removing hazards. In most cases, the preferred approach is to eliminate hazardous materials or processes and install engineering controls to reduce exposure or shield employees. Until such controls are in place, or if they are not effective or feasible, administrative measures and personal protective equipment may be needed.

\section{Engineering Controls}

Engineering controls reduce employees' exposures by removing the hazard from the process or by placing a barrier between the hazard and the employee. Engineering controls protect employees effectively without placing primary responsibility of implementation on the employee.

1. Automate the refilling of the coating tanks to reduce the need for employees to manually handle the UV-cured coating.

2. Consult with a ventilation engineer to eliminate instances of excess exhaust duct, minimize sharp angles in exhaust duct, and evaluate the location of pedestal fans and their impact on the effectiveness of the exhaust ventilation systems. A ventilation engineer should re-evaluate the effectiveness of the exhaust ventilation after these changes are made.

\section{Administrative Controls}

The term administrative controls refers to employer-dictated work practices and policies to reduce or prevent hazardous exposures. Their effectiveness depends on employer commitment and employee acceptance. Regular monitoring and reinforcement are necessary to ensure that policies and procedures are followed consistently.

1. Track and maintain records of when burnt mix events occur. These records will provide information for future efforts by the plant to determine the relationship, if any, between burnt mix and symptoms reported by employees. 
2. Communicate to employees when burnt mix events are occurring to provide an accurate, uniform understanding of when burnt mix occurs among managers and employees.

3. Ensure that employees receive training on the potential risks of exposure to burnt mix and how to protect themselves from such risks.

4. Open overhead and personnel doors as much as possible. Past industrial hygiene sampling showed reduced levels of exposures when doors were kept open.

5. Reinforce through training and signage that a dedicated UV hand cleaner should be used instead of soap and water to clean the skin after handling UV coating.

6. Encourage employees to promptly report any symptoms to supervisors. Track and follow up on reports of symptoms to further evaluate potential relationships between LVT production processes and symptoms.

7. Encourage employees to seek medical care for symptoms. This can help determine if symptoms are related to exposures at work.

8. Consider providing employees with assistance with tobacco cessation. More information about tobacco prevention and control through the workplace can be found at http:/www.cdc.gov/niosh/docs/wp-solutions/2015-202/pdfs/2015-202.pdf.

\section{Personal Protective Equipment}

Personal protective equipment is the least effective means for controlling hazardous exposures. Proper use of personal protective equipment requires a comprehensive program and a high level of employee involvement and commitment. The right personal protective equipment must be chosen for each hazard. Supporting programs such as training, changeout schedules, and medical assessment may be needed. Personal protective equipment should not be the sole method for controlling hazardous exposures. Rather, personal protective equipment should be used until effective engineering and administrative controls are in place.

1. Educate employees who use N95 respirators on a voluntary basis that they do not protect against exposures to gases such as $\mathrm{HCl}$.

2. Ensure that gloves and protective sleeves that cover the hands, wrists, and forearms are used when handling UV coating. 


\section{Appendix: Occupational Exposure Limits and Health Effects}

NIOSH investigators refer to mandatory (legally enforceable) and recommended OELs for chemical, physical, and biological agents when evaluating workplace hazards. OELs have been developed by federal agencies and safety and health organizations to prevent adverse health effects from workplace exposures. Generally, OELs suggest levels of exposure that most employees may be exposed to for up to 10 hours per day, 40 hours per week, for a working lifetime, without experiencing adverse health effects. However, not all employees will be protected if their exposures are maintained below these levels. Some may have adverse health effects because of individual susceptibility, a pre-existing medical condition, or a hypersensitivity (allergy). In addition, some hazardous substances act in combination with other exposures, with the general environment, or with medications or personal habits of the employee to produce adverse health effects. Most OELs address airborne exposures, but some substances can be absorbed directly through the skin and mucous membranes.

Most OELs are expressed as a TWA exposure. A TWA refers to the average exposure during a normal 8- to 10-hour workday. Some chemical substances and physical agents have recommended short-term exposure limit or ceiling values. Unless otherwise noted, the shortterm exposure limit is a 15-minute TWA exposure. It should not be exceeded at any time during a workday. The ceiling limit should not be exceeded at any time.

In the United States, OELs have been established by federal agencies, professional organizations, state and local governments, and other entities. Some OELs are legally enforceable limits; others are recommendations.

- The U.S. Department of Labor OSHA PELs (29 Code of Federal Regulation [CFR] 1910 [general industry]; 29 CFR 1926 [construction industry]; and 29 CFR 1917 [maritime industry]) are legal limits. These limits are enforceable in workplaces covered under the Occupational Safety and Health Act of 1970.

- NIOSH RELs are recommendations based on a critical review of the scientific and technical information and the adequacy of methods to identify and control the hazard. NIOSH RELs are published in the NIOSH Pocket Guide to Chemical Hazards [NIOSH 2010]. NIOSH also recommends risk management practices (e.g., engineering controls, safe work practices, employee education/training, personal protective equipment, and exposure and medical monitoring) to minimize the risk of exposure and adverse health effects.

- Another set of OELs commonly used and cited in the United States is the ACGIH TLVs. The TLVs are developed by committee members of this professional organization from a review of the published, peer-reviewed literature. TLVs are not consensus standards. They are considered voluntary exposure guidelines for use by industrial hygienists and others trained in this discipline "to assist in the control of health hazards" [ACGIH 2017].

Outside the United States, OELs have been established by various agencies and organizations and include legal and recommended limits. The Institut für Arbeitsschutz der Deutschen 
Gesetzlichen Unfallversicherung (Institute for Occupational Safety and Health of the German Social Accident Insurance) maintains a database of international OELs from European Union member states, Canada (Québec), Japan, Switzerland, and the United States. The database, available at http://www.dguv.de/ifa/GESTIS/GESTIS-Internationale-Grenzwerte-fürchemische-Substanzen-limit-values-for-chemical-agents/index-2.jsp, contains international limits for more than 2,000 hazardous substances and is updated periodically.

OSHA requires an employer to furnish employees a place of employment free from recognized hazards that cause or are likely to cause death or serious physical harm [Occupational Safety and Health Act of 1970 (Public Law 91-596, sec. 5(a)(1))]. This is true in the absence of a specific OEL. It also is important to keep in mind that OELs may not reflect current health-based information.

When multiple OELs exist for a substance or agent, NIOSH investigators generally encourage employers to use the lowest OEL when making risk assessment and risk management decisions. NIOSH investigators also encourage use of the hierarchy of controls approach to eliminate or minimize workplace hazards. This includes, in order of preference, the use of (1) substitution or elimination of the hazardous agent, (2) engineering controls (e.g., local exhaust ventilation, process enclosure, dilution ventilation), (3) administrative controls (e.g., limiting time of exposure, employee training, work practice changes, medical surveillance), and (4) personal protective equipment (e.g., respiratory protection, gloves, eye protection, hearing protection). Control banding, a qualitative risk assessment and risk management tool, is a complementary approach to protecting employee health. Control banding focuses on how broad categories of risk should be managed. Information on control banding is available at http://www.cdc.gov/ niosh/topics/ctrlbanding/. This approach can be applied in situations where OELs have not been established or can be used to supplement existing OELs.

\section{Hydrogen Chloride}

At room temperature, $\mathrm{HCl}$ is a colorless gas with a pungent odor. When mixed in water, it is known as hydrochloric acid. $\mathrm{HCl}$ is corrosive and can irritate the eyes, nose, throat, respiratory tract, and skin at concentrations as low as 5 ppm [Agency for Toxic Substances and Disease Registry 2014; National Research Council 2004]. A single exposure to high levels of $\mathrm{HCl}$ can lead to reactive airway dysfunction syndrome, a type of irritant-induced asthma [Boulet 1998; Gorguner et al. 2004; National Research Council 2004; Promisloff et al. 1990]. The current OSHA PEL and NIOSH REL for $\mathrm{HCl}$ is $5 \mathrm{ppm}$ as a ceiling [29 CFR 1910.1000; NIOSH 2010]. The ACGIH TLV for $\mathrm{HCl}$ is 2 ppm as a ceiling [ACGIH 2017]. The immediately dangerous to life or health concentration established by OSHA, NIOSH, and ACGIH for $\mathrm{HCl}$ is 50 ppm [29 CFR 1910.1000; ACGIH 2017; NIOSH 2010]. 


\section{References}

ACGIH [2017]. 2017 TLVs ${ }^{\circledR}$ and BEIs ${ }^{\circledR}:$ threshold limit values for chemical substances and physical agents and biological exposure indices. Cincinnati, OH: American Conference of Governmental Industrial Hygienists.

Agency for Toxic Substances and Disease Registry [2014]. Medical management guidelines for hydrogen chloride. Atlanta, GA: U.S. Department of Health and Human Services, Agency for Toxic Substances and Disease Registry, https://www.atsdr.cdc.gov/MHMI/mmg173.pdf.

Boulet LP [1988]. Increases in airway responsiveness following acute exposure to respiratory irritants. Reactive airway dysfunction syndrome or occupational asthma?

Chest 94(3):476-481, https://dx.doi.org/10.1378/chest.94.3.476.

Centers for Disease Control and Prevention [2011]. Current cigarette smoking prevalence among working adults_-United States, 2004-2010. MMWR 60(38):1305-1309.

CFR. Code of Federal Regulations. Washington, DC: U.S. Government Printing Office, Office of the Federal Register.

EPA [1999].Compendium method TO-17: determination of volatile organic compounds in ambient air using active sampling onto sorbent tubes. 2nd ed. Cincinnati, OH: Environmental Protection Agency, https://www3.epa.gov/ttnamti1/files/ambient/airtox/to-17r.pdf.

Gorguner M, Aslan S, Inandi T, Cakir Z [2004]. Reactive airways dysfunction syndrome in housewives due to a bleach-hydrochloric acid mixture. Inhal Toxicol 16(2):87-91, http://dx.doi.org/10.1080/08958370490265004.

Jaakkola JJ, Knight TL [2008]. The role of exposure to phthalates from polyvinyl chloride products in the development of asthma and allergies: a systematic review and meta-analysis. Environ Health Perspect 116(7):845-853, http://dx.doi.org/10.1289/ehp.10846.

National Research Council (US) Subcommittee on Acute Exposure Guideline Levels [2004]. Hydrogen chloride: acute exposure guideline levels. Acute exposure guideline levels for selected airborne chemicals. Volume 4. Washington, DC: National Academies Press, https://www.ncbi.nlm.nih.gov/books/NBK207738/.

Nethercott JR, Jakubovic HR, Pilger C, Smith JW [1983]. Allergic contact dermatitis due to urethane acrylate in ultraviolet cured inks. Br J Ind Med 40(3):241-250,

http://dx.doi.org/10.1136/oem.40.3.241.

Nielsen J, Fahraeus C, Bensryd I, Akesson B, Welinder H, Linden K, Skerfving S [1989].

Small airways function in workers processing polyvinylchloride. Int Arch Occup Environ Health 61(7):427-430, https://dx.doi.org/10.1007/BF00386474.

NIOSH [2010]. NIOSH pocket guide to chemical hazards. Cincinnati, OH: U.S. Department of Health and Human Services, Centers for Disease Control and Prevention, National Institute for Occupational Safety and Health, DHHS (NIOSH) Publication No. 2010-168c, http://www.cdc.gov/niosh/npg/. 
NIOSH [2013]. Workplace safety and health topics: skin exposures and effects. Cincinnati, OH: U.S. Department of Health and Human Services, Centers for Disease Control and Prevention, National Institute for Occupational Safety and Health, https://www.cdc.gov/niosh/topics/skin/.

Promisloff RA, Phan A, Lenchner GS, Cichelli AV [1990]. Reactive airway dysfunction syndrome in three police officers following a roadside chemical spill. Chest 98(4):928-929, http://dx.doi.org/10.1378/chest.98.4.928.

Willemse BW, Postma DS, Timens W, ten Hacken NH [2004]. The impact of smoking cessation on respiratory symptoms, lung function, airway hyperresponsiveness and inflammation. Eur Respir J 23(3):464-476. 
Keywords: North American Industry Classification System (NAICS) 321918 (Other Millwork [including Flooring]), Pennsylvania, Luxury Vinyl Tile, Flooring, Hydrogen Chloride, Carbon Monoxide, Nitrogen Dioxide, Nitrous Fumes, Volatile Organic Compounds, Skin, Respiratory, Irritation, Ultraviolet, UV, Skin Sensitizer, Burnt Mix 
The Health Hazard Evaluation Program investigates possible health hazards in the workplace under the authority of the Occupational Safety and Health Act of 1970 (29 U.S.C. § 669(a) (6)). The Health Hazard Evaluation Program also provides, upon request, technical assistance to federal, state, and local agencies to investigate occupational health hazards and to prevent occupational disease or injury. Regulations guiding the Program can be found in Title 42, Code of Federal Regulations, Part 85; Requests for Health Hazard Evaluations (42 CFR Part 85).

\section{Disclaimer}

The recommendations in this report are made on the basis of the findings at the workplace evaluated and may not be applicable to other workplaces.

Mention of any company or product in this report does not constitute endorsement by NIOSH.

Citations to Web sites external to NIOSH do not constitute NIOSH endorsement of the sponsoring organizations or their programs or products. NIOSH is not responsible for the content of these Web sites. All Web addresses referenced in this document were accessible as of the publication date.

\section{Acknowledgments}

Analytical Support: Maxxam Analytics

Desktop Publisher: Shawna Watts

Editor: Ellen Galloway

Industrial Hygiene Field Assistance: Gregory Burr

Logistics: Donnie Booher, Kevin Moore

Medical Field Assistance: Shilpa Gowda

\section{Availability of Report}

Copies of this report have been sent to the employer, employees, and union at the plant. The state and local health department and the Occupational Safety and Health Administration Regional Office have also received a copy. This report is not copyrighted and may be freely reproduced.

\section{Recommended citation for this report:}

NIOSH [2018]. Evaluation of health symptoms and exposures among employees at a flooring manufacturing plant. By Chiu S, Li JF. Cincinnati, OH: U.S. Department of Health and Human Services, Centers for Disease Control and Prevention, National Institute for Occupational Safety and Health, Health Hazard Evaluation Report 20160126-3301, https://www.cdc.gov/niosh/hhe/reports/pdfs/2016-0126-3301.pdf. 
Delivering on the Nation's promise:

Promoting productive workplaces through safety and health research

To receive NIOSH documents or more information about occupational safety and health topics, please contact NIOSH:

Telephone: 1-800-CDC-INFO (1-800-232-4636)

TTY: 1-888-232-6348

CDC INFO: www.cdc.gov/info

or visit the NIOSH Web site at www.cdc.gov/niosh

For a monthly update on news at $\mathrm{NIOSH}$, subscribe to

$\mathrm{NIOSH}$ eNews by visiting www.cdc.gov/niosh/eNews. 